\title{
Evolution of Information Systems Curriculum in an Australian University over the Last Twenty-Five Years
}

\author{
Arthur Tatnall $^{1}$ and Stephen Burgess ${ }^{2}$ \\ ${ }^{1}$ Graduate School of Business, Victoria University, Australia \\ Arthur. Tatnallevu.edu.au \\ ${ }^{2}$ School of Management and Information Systems, Victoria University, Australia \\ Stephen.Burgess@vu.edu.au
}

\begin{abstract}
Information Systems (IS) courses began in Australia's higher education institutions in the 1960, and have continued to evolve at a rapid rate since then. Beginning with a need by the Australian Commonwealth Government for a large number of computer professionals, Information Systems (or Business Computing) courses developed rapidly. The nature and content of these courses in the 1960s and 70s, however, was quite different to present courses and this paper traces this change and the reasons for it. After some brief discussion of the beginnings and the early days of Information Systems curriculum, we address in particular how these courses have evolved in one Australian university over the last 25 years. IS curriculum is seen to adapt, new materials are added and emphases changed as new technologies and new computing applications emerge. The paper offers a model of how curriculum change in Information Systems takes place.
\end{abstract}

Keywords: Information Systems, Business Computing, Curriculum, Change, History of Educational Computing, Higher Education.

\section{The Beginnings of Business Computing}

Fifty years ago a computer was something that few organisations could afford. The idea that many people would use their own computer at work and at home was unthinkable. Then in the 1970s, everything changed and computers began to become accessible and teaching about computers and their use became important [2]. This paper is concerned with the development of one type of computing course: Information Systems, however the boundaries between this and other aspects of computing are far from distinct. These courses could be described simply as "curricula designed primarily to educate people in the efficient and effective application of computer hardware, software, and systems to the solution of business and organisational problems" [2:1].

Australia made its move into computing early with the CSIR Mk1 (CSIRAC), built by Pearcey and Beard in the late 1940s as Australia's first internally-stored-program computer. This is acknowledged to be the world's fifth [3]. Computer Science courses began in Australia's universities of the 1950s using machines like CSIRAC, but the 
universities were then only starting to come to grips with the issue of whether computing was a part of mathematics or should be considered as a new discipline [4].

In the late 1950s the Australian Commonwealth Government took the decision to computerise the operation of the Department of Defence and the Postmaster General's Department (PMG), creating a requirement for trained computing personnel, but soon found that there were no available computing professionals to be found either in Australia or overseas.

Courses in Business Computing commenced in the 1960s due to the requirement of the Commonwealth Government for computing professionals to fulfil these growing administrative needs [5] when the Australian Commonwealth Government Public Service Board set up its own Programmer-in-Training (PIT) course. The first twelve months long PIT course ran in 1965, drawing upon the Defence Department staff's experiences with both computerised and existing non-computerised, administrative systems. The forty-six week PIT course covered the following formal topics: Introduction to the Course and Public Service, Computer Equipment and Techniques-1 \& 2, Computer Mathematics-1 \& 2 (Statistics), Programming-1 \& 2, Systems Analysis and Design-1 \& 2. There were also 24 weeks of on-the-job training. PIT courses continued, under the Commonwealth Public Service Board until late in the 1960s when responsibility was transferred to the Higher Education sector [5]. These courses set the style for many of the courses later offered in Higher Education in Australia [6]. On the significance of the Commonwealth's initiatives to Higher Education, Pearcey notes that:

In many of these institutions, teaching in computing started as a result of the staffing crisis that arose first from the Defence and PMG's projects.

\section{Modelling Computing Curriculum Development}

During the period from the late 1960s until the mid 1980s, Information Systems curriculum could be considered to have passed through a number of different phases as new technologies developed: one such change was the move from punch-cards to mini-computer terminals and then to the PC. A major change was due to growth in the use of computers in business and the development of many new business applications. In the early days of computing there was not much that you could do with a computer if you did not know how to program it. Even before Information Systems became popular as a discipline in its own right, some business courses taught computer skills and programming. One of the most popular languages was the third generation language BASIC, which (for example) was offered by a number of universities on punched card' that were then sent to Monash University for overnight processing on their Monecs computer - with the results of the program's processing returned to the institution the next morning. The production of new application software, typically running on personal computers, however, began to change all of this and Information Systems curriculum needed to adapt to all of these changes. 


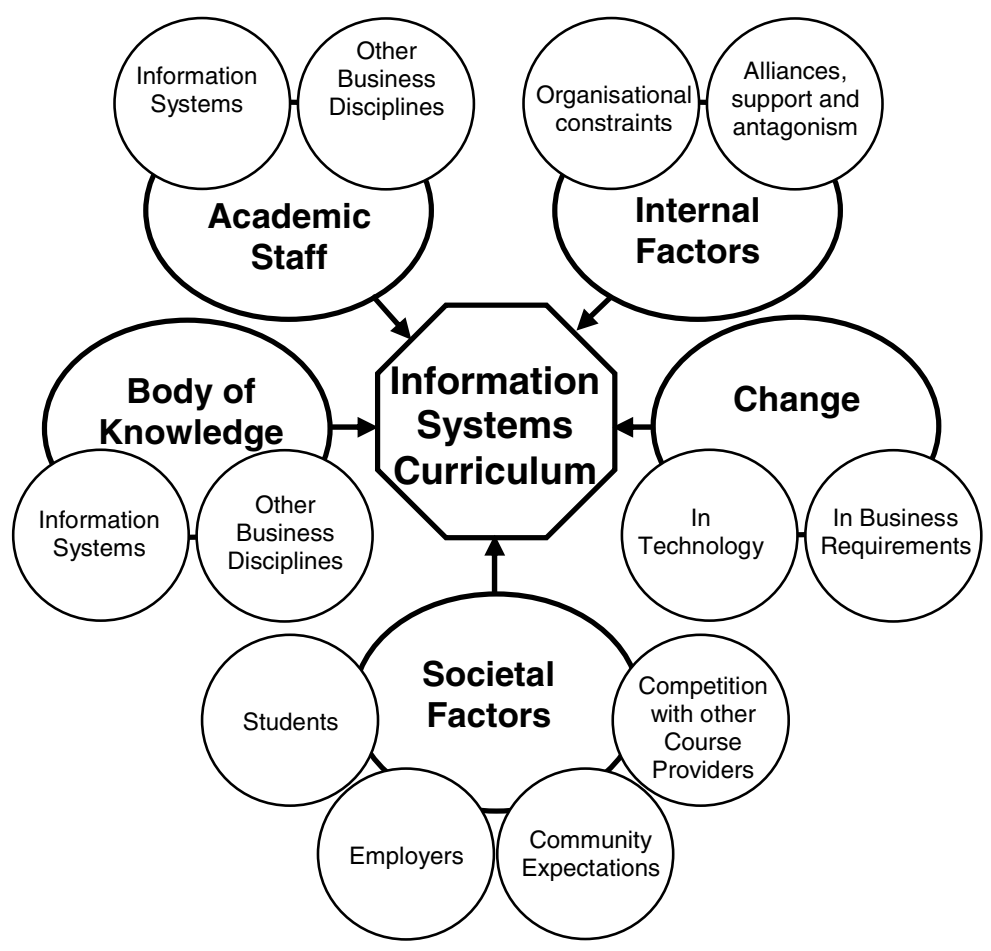

Fig. 1. Factors Influencing the Development of Information Systems Curriculum (adapted from Tatnall [1])

The mission of a university Department of Information Systems is quite clear: it must research, investigate and teach how businesses, and other organisations, can make the best use of computers and Information Technology (IT) to further their business and organisational aims [2]. By its very nature, Information Systems (IS) is an applied discipline that is closely related to the use of information technology in business applications. Many factors influence the direction of Information Systems curriculum development as we have indicated in the model above (Figure 1). What is more, these factors do not act singly but in combination, making a holistic view of their influence essential [8]. Information Systems, as a discipline in its own right, is seen to be separate from Computer Science in that it concentrates upon the sociotechnical aspects surrounding the implementation and use of ICT in organisations rather than the technical side of systems development. This does not mean that the more technical aspects of Computer Science do not have a place in Information Systems as the disciplines do overlap and those boundaries are often blurred.

Layton [9] has developed a three-stage model for the evolution of school subjects in nineteenth century England. While Layton's model has been shown to be useful in examining slow subject evolution, it has also been shown to be of limited use in describing the rapid emergence and evolution of curricula in Information Systems [5]. Layton has argued that for new subjects: 
1. The new subject area is justified on grounds of pertinence and utility. Learners are attracted because it bears on matters of concern to them. Teachers are rarely trained specialists, but bring the "missionary enthusiasms of pioneers" to their task.

2. Next a tradition of scholarly work emerges and teachers become trained specialists. Students are attracted "as much by its reputation and growing academic status as by its relevance to their own problems and concerns".

3. Finally, the teachers move to constitute a professional body with established rules and values, and subject matter is selected on the "judgements and practices of the specialist scholars who lead inquiries in the field".[9]

In the remainder of this paper we will consider the evolution of Information Systems at Victoria University in Melbourne, Australia. Victoria University (VU) is a relatively new institution formed in 1991 by the merger of two Colleges of Advanced Education (CAE): Footscray Institute of Technology (FIT) and Western Institute (WI). We will begin by considering events at Footscray Institute of Technology in the mid 1980s.

\section{Information Systems Curriculum at Footscray Institute in the 1970s and Early 1980s}

In the early 1980s FIT updated its Associate Diploma in Secretarial Practice to include a substantial computing component: word processing, office automation, use of computer technology and electronic mail. In 1984 the new Bachelor of Business in Information Management and Communication took its first students.

The course was pioneering at the time in that it attempted to stress that "information is a critical organisational resource that must be managed effectively and efficiently", rather than one concentrating on 'pure computing' where a study of the technology involved was seen as the priority. As well as a major in Information Management, the course had a compulsory minor in more traditional computing programming, systems analysis and systems development. Students were, however, encouraged to do a double major of both Information Management and Computing. At that stage the term 'Information Management' referred to recognition that information that flowed into, out of and within an organisation was a resource that needed to be managed. The earlier office automation focus thus needed to be updated as the notion of information as a resource had become a major focus. The updated area became known as Information Management.

Around this time, traditional Business Computing (later Information Systems) curricular was beginning to develop and most courses had a core of similar topics which were typically based around subjects related to systems analysis and design, database design, business programming (which at that stage was typically done using third generation such as BASIC, COBOL or Pascal) and systems implementation. Many of these courses at the time also had an introductory computer networking unit which was probably the most technical and close to the discipline of Computer Science. The subjects handling computer architecture were probably well into the realm of Computer Science and were often electives. 
By the late 1980s, there was growing support for the development of a computing course and the Bachelor of Business (Information Technology) was launched with two strands: Information Management and Computing (Systems Development). Students were again encouraged to take subjects from both strands.

\section{Information Systems Curriculum at Victoria University from the Early 1990s - 2000}

At the start of this period the two CAEs were in the process of merging their courses to form a single university. While FIT had concentrated on Information Management, WI had taken a more traditional line in business computing. These streams needed to merge, and in the process several new areas emerged.

\subsection{Information Management}

As already mentioned in the late 1980s and early 1990s a number of courses were being developed around the notion of Information Management. At the time, [10] suggested that such courses should not be limited to one discipline, should prepare students with skills for tomorrow and should not be technology bound - their argument being that technological obsolescence occurred too quickly. Garrison [11] also noted that Information Management courses were emerging out of many disciplines such as the Library and Information Science, Business and Computer Science (in addition to Office Automation).

In discussing what should be included in these courses Laverty and Sorg [12] identified three levels of computer-related knowledge and skills they considered should be possessed by people charged with the task of managing the acquisition and use of IT and/or the management of information resources:

- Basic skills allowing use of the computer

- Ability to manage technology as an organisational resource

- Ability to implement IT policy: its promotion, implications of its use and an understanding of its impact on economic, political and the social climate.

It is thus clear that the links between the management of information as a resource and the use of IT to do this were being established. In its first incarnation (after evolving from an office automation degree), the Information Management subjects primarily addressed the use of IT within the organisation, the role of knowledge workers (another term coined at this time), methods for storage and retrieval of information within the organisation (using IT and more traditional means such as paper records), and other phases of the information life cycle (creation, processing, dissemination and disposal of information). A subject related to Information Systems Management was also introduced.

\subsection{Skills of Information Professionals}

One important notion that emerged during this time was the need for a new brand of professional: the Information Professional. These professionals would have skills that spanned a number of fields: some of the technical skills of traditional computing personnel, an understanding of the concept of information as a resource to be managed 
within the organisation, an understanding of the strategic role that IT was beginning to play in the organisation, the ability to communicate (both orally and in written form) with other professionals within the organisation and with senior managers, and an appreciation of their own role as professionals. These last two areas in particular highlighted a greater appreciation of the importance of IT and Information Management within the organisation and recognition of the importance of the roles of those who performed in these arenas [13]. To this end a subject was introduced (and still exists within current undergraduate and postgraduate degrees) known as The Information Professional, which highlighted the development of interpersonal skills, an understanding of the role of the information (now IT) professional and an appreciation of the importance and role that professional organisations play in promoting good practice and awareness in the IT profession [13].

\subsection{IT Project Management}

While most IS professionals spend much of their time in the implementation or management of projects, the curriculum of university IS courses does not always reflect this [14]. Although there had been some awareness of the need to include materials related to the management of IT projects in the curricula [13] this did not occur until 1994 with the introduced of a new undergraduate final year subject: 'Systems Implementation'. The initial motivation for this was use, by two IS academics [15], of Microsoft Project software in planning an academic conference the year before. Seeing the value of this software they then worked out a way to introduce it into the curriculum for the degree course. A postgraduate subject in 'IT Project Management' was introduced several years later.

\subsection{Visual Programming Languages}

Although the standard business computing curricula had included programming with third generation languages for a number of years, new forms of programming (based around personal computer databases) meant that the ability to build applications was becoming the domain of PC users in organisations, and not just the IT experts. It was necessary to reflect this in the curriculum. As well as IT project management, the content of 'Systems Implementation' included database programming (in dBase IV) and the use of Visual Basic (VB) to create information system front-ends. One of the authors, along with a colleague from another university, had recently discovered Visual Basic and were impressed by the ease with which simple, but powerful and good looking applications could be built up [16, 17]. VB was chosen as environments of this type were beginning to be quite widely used in organisational settings involving client-server systems and Visual Basic was able to easily extract data from a variety of external sources.

\section{Information Systems Curriculum at Victoria University from 2000 - The Present}

In this period two significant new curriculum areas emerged, mainly due to the efforts of a small number of academic staff. The way that each of these areas came into being closely parallels the first two stages of Layton's [9] model. 


\subsection{Electronic Commerce}

Towards the end of the 1990s the Head of the School of Information Systems decided to introduce an undergraduate electronic commerce degree after being asked by senior management to identify new growth areas for the university, and academic staff were charged with developing this. It was decided to proceed along traditional IS lines with ' $\mathrm{e}$ ' versions of database, systems analysis, systems design, programming and even networking subjects. It was initially decided to offer the course only at one of the university's outer campuses and this was not popular with students. New enrolments were encouraging without ever being significant. Not long after the time of the 'dotcom' crash a decision was made to move the course to another campus but then (as with many other e-commerce courses in the country), student numbers began to drop and the course was discontinued in 2008. Compounding this decision was the fact that, as with e-commerce in industry, many of the 'e' aspects of Information Systems had by then become mainstream (and thus part of the main curricula) over time.

The approach to postgraduate e-commerce offerings was more conservative. Several new postgraduate e-commerce subjects were introduced in 2000 for the MBA and Master of Business (Information Systems), in response to what we, and a number of our colleagues, saw as the growth in business importance of this topic $[18,19]$.

- 'Internet Commerce' - the introductory subject provided an overview of how business is conducted over the Internet. It looked at technological and infrastructure requirements and business and management issues.

- 'Internet Technologies in Business' - examined ways that business could use these technologies for communication and business research, as well as technologies such as intranets and firewalls to improve its own business processes and store business documents.

- 'Building Internet Commerce Systems' - explored the use of HTML and other mark-up languages, design issues, scripting and programming for the Internet, Web databases, implementation options, and Internet design.

- 'Executive and Mobile Computing' introduced technologies that support managerial work / decision making, particularly for the business executive away from the office and on the move, but needing to always keep in touch.

- 'Small Business Information and Internet Systems' covered a broad range of topics relating to the use of the Internet by small business, with students building small business systems using recorded macros, along with Visual Basic for Applications (VBA) programs [20, 21].

Some of these subjects also served as electives for the university's MBA program. A few years into the new millennium these subjects were combined with others to form combined marketing/e-business and standalone e-business programs masters programs. The reduction in demand for e-business programs and a rationalisation of programs within the university meant that these were also discontinued in 2008.

\subsection{Enterprise Resource Planning (ERP)}

Around 2000 one of the School's academic staff developed an interest in SAP's Enterprise Resource Planning software. He soon managed to convince a number of his 
colleagues that ERP would be a worthwhile addition to the curriculum, and began agitating for this. It was first necessary, however, to have access to the software so he used his contacts to convince SAP (a German software company) to set up an agreement with the university to make use of SAP software in its new ERP courses, which spanned both the IS and management areas. ERP is now thriving at both undergraduate and postgraduate levels.

\section{Modelling the Evolution of IS Curriculum at VU}

While the various IS Model Curricula [22-24] are often seen as the drivers for curriculum development, this has not been the case at VU. While they were certainly examined, new subject initiatives came, in each instance, from one or two academics who had developed an interest in the area and enthusiastically promoted it. This is in line with Layton's first stage of new subject development.

Once a subject area has entered the curriculum, however, it is not assured of remaining there for ever. For example, by 2008 not much visual programming was taught as emphasis in IS course moved away from the teaching of programming of any type. Speaking of masters level courses in business containing some component of e-commerce, Melymuka [25:48] notes that these all have several things in common: "They've been cobbled together in record time, they're evolving by the minute, they're wildly popular with students, and they will probably disappear in five years." What we have seen at VU tends to supports this view as much of the material presented in these e-commerce subjects has now disappeared into the background of traditional subjects.

It is doubtful whether many Information Systems subjects will ever move fully into Layton's third stage as this would amount to stagnation, and this is certainly not an area where there is any immediate danger of this happening.

\section{References}

1. Tatnall, A.: Innovation and Change in the Information Systems Curriculum of an Australian University: a Socio-Technical Perspective, Central Queensland University: Rockhampton (2000)

2. Tatnall, A.: Curriculum Cycles in the History of Information Systems in Australia. Heidelberg Press, Melbourne (2006)

3. McCann, D., Thorne, P.: The Last of the First - CSIRAC: Australia's First Computer. The University of Melbourne, Melbourne (2000)

4. Tatnall, A., Davey, B.: Streams in the History of Computer Education in Australia. In: Impagliazzo, J., Lee, J.A.N. (eds.) History of Computing in Education. IFIP, pp. 83-90. Kluwer Academic Publishers, Assinippi Park (2004)

5. Tatnall, A.: A Curriculum History of Business Computing in Victorian Tertiary Institutions from 1960 - 1982, in MA thesis, Education, Deakin University, Geelong (1960)

6. Maynard, G.: Interview on the History of Business Computing. Melb (1990)

7. Pearcey, T.: A History of Australian Computing. Chisholm Institute of Technology, Melbourne (1988) 
8. Tatnall, A.: Socio-Technical Processes in the Development of Electronic Commerce Curricula. In: Wenn, A. (ed.) Skilling the e-Business Professional, pp. 9-21. Heidelberg Press, Melbourne (2002)

9. Layton, D.: Science as General Education. Trends in Education (1972)

10. Moll, J.K., Flood, B.J.: Information Science and Information-Related Educational Programs: their Diversity and Accreditation. Journal of the American Society for Information Science, 318-322 (September 1988)

11. Garrison, G.: Challenges to Information Science Education. Journal of the American Society for Information Science 39(5) (1988)

12. Laverty, E.P., Sorg, J.S.: Information Technology and Education for the Public Service. International Journal of Public Administration 8(4), 391-408 (1986)

13. Burgess, S.: Curriculum Planning for Information Management, in Business Information Technology. Royal Melbourne Institute of Technology: Melbourne (1993)

14. Tatnall, A., Reyes, G.: Teaching IT Project Management to Postgraduate Business Students: a Practical Approach. Journal of Information Technology Education 4, 153-166 (2005)

15. Tatnall, A., Shackleton, P.: Project Management Software: the Fourth Tool? In: Software Education Conference: SRIG-ET 1994. IEEE Computer Society Press, Dunedin (1995)

16. Davey, B., Tatnall, A.: Introducing Object Environments: Cognitive Difficulties. In: Software Education Conference: SRIG-ET 1994. IEEE Computer Society Press, Dunedin (1995)

17. Davey, B., Tatnall, A.: Tools for Client-Server Computing. In: Purvis, M. (ed.) Software Engineering: Education and Practice, pp. 280-285. IEEE Computer Society Press, Los Alamitos (1996)

18. Burgess, S., Tatnall, A.: Post Graduate Electronic Commerce Specialisations: an Australian University Case Study. In: Innovation Through Information Technology (IRMA). IGI, New Orleans (2004)

19. Tatnall, A., Groom, C., Burgess, S.: Electronic Commerce Specialisations in MBAs: an Australian University Case Study. In: Informing Science and IT Education Conference. University College Cork, Cork (2002)

20. Burgess, S., Tatnall, A., Darbyshire, P.: Teaching Small Business Entrepreneurs about Computers. In: EuroPME - Entrepreneurship: Building for the Future. Groupe ESC, Rennes (1999)

21. Tatnall, A., Burgess, S.: Experiences in Building and Using Decision-Support Systems in Postgraduate University Courses. Interdisciplinary Journal of Information, Knowledge, and Management 2, 33-42 (2007)

22. ACM, IT-2008 ACM Computing Curriculum, Information Technology volume. Association for Computing Machinery, New York (2008)

23. Joint Task Force on Computing Curricula. IS 2002 - Model Curriculum and Guidelines for Undergraduate Degree Programs in Information Systems (2002),

http: / /www.acm.org/education/is2002.pdf

24. Joint Task Force on Computing Curricula. Computing Curricula 2005 - The Overview Report covering undergraduate degree programs in Computer Engineering, Computer Science, Information Systems, Information Technology and Software Engineering, http://www.acm.org/education/curric_vols/ CC2005-March06Final.pdf

25. Melymuka, K.: Mastering E-Commerce by Degrees. In: Computerworld, pp. 48-49 (2000) 